\title{
Exposure to waves enhances the growth rate and nitrogen status of the giant kelp Macrocystis pyrifera
}

\author{
Christopher D. Hepburn ${ }^{1, *}$, James D. Holborow ${ }^{2}$, Stephen R. Wing ${ }^{2}$, \\ Russell D. Frew ${ }^{3}$, Catriona L. Hurd ${ }^{1}$ \\ ${ }^{1}$ Department of Botany, ${ }^{2}$ Department of Marine Science, and ${ }^{3}$ Department of Chemistry, University of Otago, PO Box 56, \\ Dunedin 9015, New Zealand
}

\begin{abstract}
The influence of wave-exposure on the growth and erosion rates of Macrocystis pyrifera was determined in Paterson Inlet, Stewart Island, New Zealand, for each season of 2002. During autumn, following a period of low seawater nitrogen, sites that received significant amounts of oscillatory flow from waves exhibited higher frond growth rates than at wave-sheltered sites. Blade and stipe growth rates at wave-exposed sites were at a yearly maximum during this period, and were 4.3 and 1.6 times higher respectively than at wave-sheltered sites where growth was at a yearly minimum. During this time C:N ratios and nitrogen concentrations of blade tissues indicated that the nitrogen status of frond apices, where the majority of growth occurs, was greater at wave-exposed sites than at wave-sheltered sites. During periods when kelp tissue nitrogen levels are low, but some inorganic nitrogen is available in the water column, oscillatory flow may enhance nutrient uptake by M. pyrifera by increasing the flux of nutrients into kelp canopies and by reducing the size of diffusion boundary layers at the kelp surface. Exposure to waves also modified the seasonal pattern of $M$. pyrifera growth by ameliorating the negative effect of low seawater nitrogen concentrations during summer and autumn. Blade and stipe growth was relatively steady at wave-exposed sites during the study period, while wave-sheltered sites had distinct seasonal patterns with low growth during summer and autumn, increasing through winter to spring maxima. In this system, water motion influences the growth rates of $M$. pyrifera only at specific times of year; when tissue nitrogen levels are low but some inorganic nitrogen is available in the water column.
\end{abstract}

KEY WORDS: Macroalgae $\cdot$ Nitrogen $\cdot$ Water motion $\cdot$ Mass-transfer $\cdot$ Waves $\cdot$ Seasonal growth Kelp $\cdot$ Macrocystis

\section{INTRODUCTION}

Patterns of macroalgal growth and productivity are attributed to variations in light, nutrient supply and temperature (e.g. Hanisak 1983, Davison 1991, Franklin \& Forster 1997). Of these factors, the role of nutrient supply is, arguably, the most poorly understood because it requires knowledge of both nutrient concentrations in the surrounding seawater and the rate of transport of those nutrients to the seaweed surface. Water motion can have a strong influence on the uptake of essential ions and dissolved gases by macroalgae (Wheeler 1980, Gerard 1982a, Hurd et al. 1996), thereby affecting their photosynthesis (Wheeler 1980, Koehl \& Alberte 1988, Koch 1993, Stewart \& Carpenter 2003) and perhaps their nutrient status, growth, and productivity. The rate of delivery of nutrients to the macroalgal surface is ultimately controlled by the thickness of the diffusion boundary layer, a region that resides within the viscous sublayer of the velocity boundary layer, and within which the movement of molecules is by molecular diffusion (Hurd 2000, San- 
ford \& Crawford 2000). In slow mainstream flows $(<6$ to $10 \mathrm{~cm} \mathrm{~s}^{-1}$ ), thicker diffusion boundary layers can lead to slower nutrient fluxes, termed mass-transfer limitation (Hurd 2000). However, the rate of movement of nutrients across the diffusion boundary layer is also directly related to the concentration of the nutrient in the seawater (Fick's first law) and the metabolic demand of the macroalga.

Mass-transfer limitation has been shown to have important impacts on the nutrient acquisition and metabolism of coral reef (Carpenter et al. 1991, Falter et al. 2004) and seagrass (Thomas et al. 2000) communities. For marine macroalgae, it is well known from laboratory experiments that increasing rates of mainstream seawater flow increases rates of uptake of essential ions and dissolved gases (Wheeler 1980, Gerard 1982a, Hurd et al. 1996) thereby affecting photosynthesis (Wheeler 1980, Koehl \& Alberte 1988, Koch 1993, Stewart \& Carpenter 2003). Furthermore, rates of macroalgal growth have been correlated to increasing levels of water motion in laboratory experiments (e.g. Parker 1982, Fujita \& Goldman 1985). However, the only in situ studies that have measured macroalgal growth rates in different hydrodynamic habitats compared a wave-exposed and a wave-sheltered site and found no clear influence of water motion on growth (Gerard \& Mann 1979, Sjøtun et al. 1998). Therefore, at present there is no field evidence of mass-transfer limited growth for macroalgae.

Our goal was to determine if there is any evidence of mass-transfer limitation of seaweed populations in situ, and if seasonal patterns of kelp growth and nitrogen status can be modified by the fluid environment in which they grow. We compared the growth rate of the canopy-forming giant kelp Macrocystis pyrifera in wave-exposed sites versus sites protected from significant oceanic wave action. $M$. pyrifera was selected for this study for several reasons. Productive and diverse M. pyrifera forests are often an important component of hard-bottomed shallow subtidal areas of southern New Zealand and many other temperate regions in both the northern and southern hemispheres (reviewed in Dayton 1985, Foster \& Schiel 1985, Steneck et al. 2002). M. pyrifera also grows over a range of hydrodynamic environments, from sheltered bays to sites that are subject to strong tidal currents and moderate wave exposure, and it is a seasonal responder showing patterns of growth closely correlated to the combined effects of light and nitrogen (Kain 1989). The majority of the biomass of $M$. pyrifera is distributed in dense canopies at the water's surface (Nyman et al. 1983), allowing the measurement of most important growth parameters from aboard a small boat.

Evidence that the growth of Macrocystis pyrifera can be limited by nitrogen has been observed throughout its geographic range (e.g. Zimmerman \& Kremer 1984, van Tussenbroek 1989, Brown et al. 1997), and like many temperate regions, the coastal waters of southern New Zealand experience predictable periods of low seawater nitrogen concentration during summer (e.g. Brown et al. 1997, Hepburn \& Hurd 2005). It was hypothesized that $M$. pyrifera growth would be masstransfer limited in wave-sheltered sites only during the summer period of low nitrogen, while outside this period high nitrate concentrations would saturate its growth requirements.

Sources of nutrients to macroalgae may also vary with water motion and influence seaweed growth rates under different hydrodynamic regimes (Hurd 2000). Reduction in seaweed production due to diffusion boundary layers in wave-sheltered sites may be offset by a change in nutrient supply to the macroalgae that cannot be detected simply by monitoring the seawater nutrient concentration. For example, in slow flows, localized sources of nitrogen such as ammonium provided by marine invertebrates living on macroalgal surfaces (Gerard \& Mann 1979, Taylor \& Rees 1998) may be a more important nitrogen-source to macroalgae than nitrate. Similarly, carbon dioxide is considered the primary carbon source in wave-exposed sites while bicarbonate may be more important in slow flows (France \& Holmquist 1997). Stable isotope ratios $\left({ }^{13} \mathrm{C}:{ }^{12} \mathrm{C}\right.$ and $\left.{ }^{15} \mathrm{~N}:{ }^{14} \mathrm{~N}\right)$ can help determine sources of nitrogen and carbon to macroalgae (Handley \& Raven 1992, Raven et al. 1995). In this study, stable isotope signatures of Macrocystis pyrifera blade tissue were used to determine any changes in nutrient sources that occurred between wave-exposed and wave-sheltered sites.

\section{MATERIALS AND METHODS}

Study sites. This study was conducted in shallow subtidal environments around the entrance of Paterson Inlet on the northeastern coast of Stewart Island, which is situated off the south coast of the South Island of New Zealand (Fig. 1). Four replicate sites exposed to significant wave action from ocean swells (E1 to E4) and 4 sites sheltered from wave action (S1 to S4), other than wind chop generated within Paterson Inlet, were selected. Sites had mean depths of 4 to $5 \mathrm{~m}$ at high tide and were dominated by the giant kelp Macrocystis pyrifera. Site selection was based on the position of the site relative to prevailing swell. The bull kelp Durvillaea antarctica (Order Fucales), a species exclusively found on wave-exposed shores, was also used as a biological indicator to determine if sites received high wave action.

Seawater nutrient concentrations. Seawater nitrate, ammonium and phosphate concentrations were deter- 


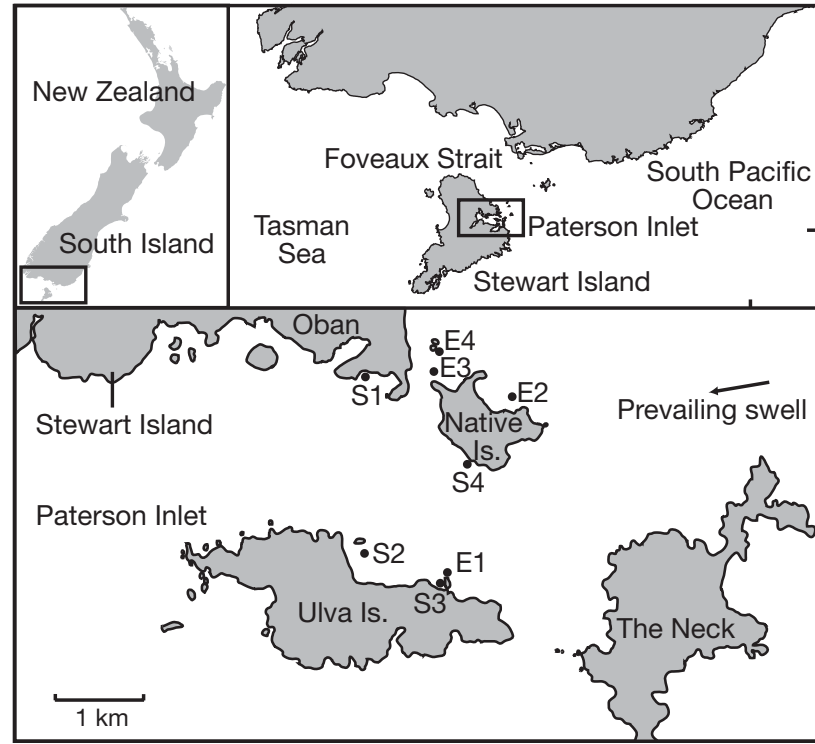

Fig. 1. Stewart Island and Paterson Inlet with locations of (E1 to E4) wave-exposed and (S1 to S4) wave-sheltered study sites

mined from each trip to Paterson Inlet. Five seawater samples were collected from the surface and at a depth of $4 \mathrm{~m}$ at all sites within a $1 \mathrm{~h}$ period to minimize the influence of any temporal changes in nutrient concentration. Samples were filtered (Whatman ${ }^{\mathrm{TM}}$ GF/C filters) and then frozen for transport to the laboratory where nitrate, ammonium, and phosphate concentrations were determined using a Lachat Quickchem ${ }^{\circledR}$ 8000 automated ion analyser.

Dissolution of gypsum blocks. The dissolution rates of gypsum blocks $\left(2 \mathrm{~cm}^{3}\right)$ were used to estimate masstransfer rates at the surface of Macrocystis pyrifera blades throughout kelp beds at each of the 8 sites. The gypsum-dissolution technique is appropriate for determinations of mass-transfer rates in different flow environments (Porter et al. 2000). Dissolution rates were determined on 3 separate occasions (in January, March, and July 2002) and were conducted during relatively calm conditions, as it was difficult to work in wave-exposed sites during high wind. Using fine copper wire, 5 blocks of a known weight were attached flush to blade surfaces in the surface canopy at a depth of $1 \mathrm{~m}$ and 5 blocks beneath the surface canopy $1 \mathrm{~m}$ above the benthos. After $24 \mathrm{~h}$, the blocks were collected and dried at $80^{\circ} \mathrm{C}$ and once their weights stabilized, these were recorded.

Macrocystis pyrifera blade morphology. Morphological characters of $M$. pyrifera blades and air bladders (pneumatocysts) can be modified by water motion (Hurd et al. 1996) and can provide an estimate of the characteristics of water motion at the blade surface over a scale of weeks to months. A range of blade morphological parameters were determined at all 8 sites during January 2002 using the methods of Hurd et al. (1996). Mature blades were collected by selecting the 10th free blade down the frond from the apical meristem of 10 haphazardly selected fronds from each site. Blade and bladder width, length, and length:width ratio were determined as well as blade thickness, number and height of corrugations, number of spines, and the angle of the blade as it joined the bladder (from here on termed base angle; see Hurd et al. 1996 for further details).

Macrocystis pyrifera growth and erosion rates. Growth rates were determined for $M$. pyrifera for 4 periods of 2002: 20 January to 9 February (summer), 6 February to 7 March (autumn), 2 June to 14 July (winter), 29 September to 4 November (spring). Twenty M. pyrifera individuals were haphazardly selected at each of the 8 study sites on each tagging date. A frond was selected from each individual that was at the water's surface and had a healthy apical meristem. The top sections of the fronds were pulled aboard a small boat for tagging with labelled flagging tape. Relative growth rates of the blade and stipe, blade erosion, and production of new blades at the apical meristem were determined using methods modified from Hepburn \& Hurd (2005). One tag (Tag 1) was placed directly behind the apical meristem and used to determine new blade production by the apical meristem, and a second tag (Tag 2) was tied at the base of the air bladder of the 5th blade down the frond (Fig. 2). Blade growth was measured by cutting a small circular hole $\left(0.5 \mathrm{~cm}^{2}\right)$ approximately $10 \mathrm{~cm}$ from the bladder-blade junction using a leaf corer, and the distance between the bladder-blade junction and the inside of the punched hole was then measured to the nearest $\mathrm{mm}$. Blade erosion was determined by measuring from the inside of the punched hole to the blade tip. Stipe growth was determined by measuring the distance between the junction of the stipe and the bladder of the tagged blade to the first bladder-stipe junction below tag one.

After approximately 1 mo (dependent on weather), tagged fronds were cut below Tag 2 by divers, carefully untangled, and placed in large plastic bags for transport to a field laboratory on Stewart Island. New blades produced in front of Tag 1 directly behind the apical scimitar were counted. Tagged blades and the stipe were re-measured and daily relative growth rates of the blades and stipe were determined (Hepburn \& Hurd 2005). Blade erosion was expressed in cm eroded $\mathrm{d}^{-1}$, while new blade production by the apical meristem was expressed in the number of new blades $\mathrm{d}^{-1}$.

Macrocystis pyrifera carbon and nitrogen status and isotopic composition. The 5th blade down the 


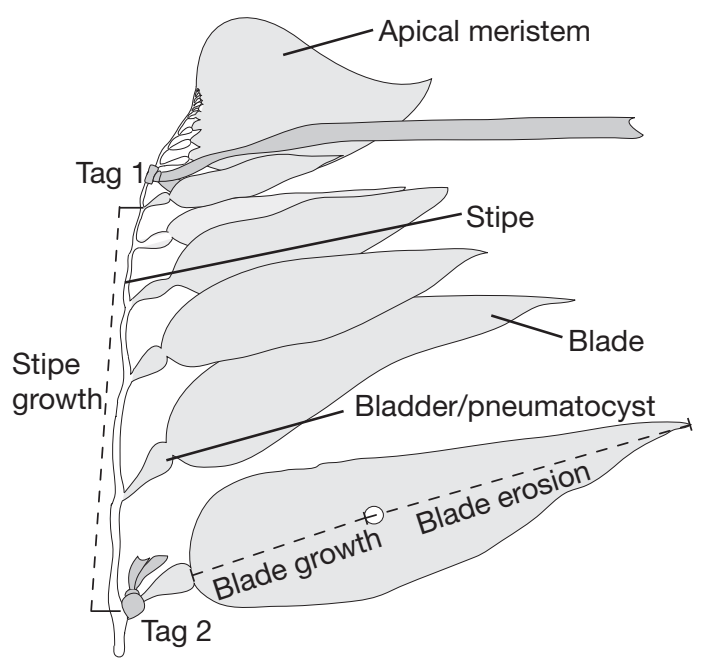

Fig. 2. Macrocystis pyrifera. Position of tags and growth measurements on each frond. Tags were tied loosely so as not to restrict frond growth

stipe from the apical meristem (after collection of the frond) was taken from each tagged M. pyrifera frond for determinations of nitrogen and carbon status and isotopic composition. Mature blades from $0.5 \mathrm{~m}$ above the benthos were haphazardly selected from 10 separate $M$. pyrifera individuals in the tagging area. Sections of blade $\left(25 \mathrm{~cm}^{2}\right)$ were cut from the actively growing basal region of each blade, carefully washed and placed in plastic centrifuge tubes before being frozen for transport and storage before analysis. Samples were then dried at $80^{\circ} \mathrm{C}$ and ground in a $10 \% \mathrm{HCl}$ washed mortar and pestle (washed with purified water between samples) and placed in sealed eppendorf $(2 \mathrm{ml})$ tubes for storage prior to determinations of total carbon and nitrogen, C:N ratio, $\delta^{13} \mathrm{C}$, and $\delta^{15} \mathrm{~N}$ of blade tissue. Sub-samples of dried, ground M. pyrifera tissue (1 to $2 \mathrm{mg}$ ) were combusted in a CE NA1500 Elemental Analyzer (Carlo-Erba ${ }^{\circledR}$ instruments) interfaced to a Europa Scientific ${ }^{\circledR}$ 20-20 update continuous flow mass spectrometer. Corrections for drift were made automatically every 5 samples from a standard (EDTA) with a known isotopic ratio. Ratios of ${ }^{15} \mathrm{~N}:{ }^{14} \mathrm{~N}$ and ${ }^{13} \mathrm{C}:{ }^{12} \mathrm{C}$ are expressed in standard $\delta$ notation. Blade tissue samples were collected during each tagging period but analysis of tissue collected during February was only conducted when clear differences in $M$. pyrifera growth were observed among sites.

Statistical analyses. Differences in Macrocystis pyrifera frond growth and erosion rates among and within the 4 tagging periods were determined using 2-way ANOVA (general linear model) with hydrodynamic regime and tagging date as independent factors and growth/erosion parameters as dependent factors. Two-way ANOVA (balanced design) was used to determine differences in dissolution rates of gypsum blocks between regimes (wave-exposed versus wavesheltered) and block depths (canopy versus subcanopy), within sites as independent factors and dissolution rates as a dependent factor. Differences between the carbon and nitrogen status (\% nitrogen and carbon, C:N ratio) and composition $\left(\delta^{13} \mathrm{C}, \delta^{15} \mathrm{~N}\right)$ of $M$. pyrifera fronds in wave-exposed and -sheltered and canopy versus subcanopy blades during January were also determined using 2-way ANOVA (balanced design). Differences among means were determined using Tukey's honestly significantly different (HSD) post-hoc test. Parametric $t$-tests were used to determine differences in blade morphology between environments. Significance was set at the $5 \%$ level $(\alpha=0.05)$. All data fulfilled prerequisites of normality (KolmogorovSmirnov test with the Lilliefors correction) and equal variance (Levene median test) for parametric tests. All statistical analyses were carried out using the software package SigmaStat ${ }^{\circledR} 2.03$ (SPSS).

\section{RESULTS}

\section{Seawater nutrients}

Only seawater nitrate concentrations showed a clear seasonal pattern, with low concentrations during summer (January to February) increasing to high concentrations during winter (June to July) (Fig. 3A). Seawater ammonium concentrations were quite variable both within and among sites and there was no obvious seasonal pattern (Fig. 3B). Phosphate concentrations were consistent among sites and seasons, an exception was observed during January (summer) when phosphate concentrations were higher, averaging $4 \mu \mathrm{mol} \mathrm{l}^{-1}$ (Fig. 3C). Seawater nutrient concentrations were similar between wave-exposed and wave-sheltered sites particularly during the summer low nitrate period. Seawater nutrient concentrations were also similar for water samples taken at the surface and at $4 \mathrm{~m}$.

\section{Estimates of mass-transport rates}

A consistent pattern of higher percentage weight loss of dissolution blocks as an indicator of mass-transfer rates at the surface of Macrocystis pyrifera blades was observed at wave-exposed sites compared to wavesheltered sites (Fig. 4, Table 1). Dissolution rates were approximately $30 \%$ higher at wave-exposed sites at the surfaces of $M$. pyrifera blades for both canopy and sub-canopy blades than at wave-sheltered sites over all sampling periods. Rates of weight loss were also significantly lower for dissolution blocks attached to 
blades within the canopy approximately $1 \mathrm{~m}$ from the water's surface than those for blocks $1 \mathrm{~m}$ from the benthos for both wave-exposed and wave-sheltered sites. The only exception to this trend was during March (autumn) when dissolution rates were not significantly different between the canopy and the sub-canopy for wave-sheltered sites.

\section{Macrocystis pyrifera blade morphology}

The only significant morphological difference observed between regimes was that blades from waveexposed sites exhibited greater base angles $\left(118^{\circ}\right)$ than those from wave-sheltered sites $\left(97^{\circ} ; t\right.$-test, $t=-6.038$, $\mathrm{p} \leq 0.001)$.

\section{Macrocystis pyrifera growth and erosion rates}

Macrocystis pyrifera frond growth rates were significantly higher at wave-exposed than at wave-sheltered sites during autumn for all parameters measured

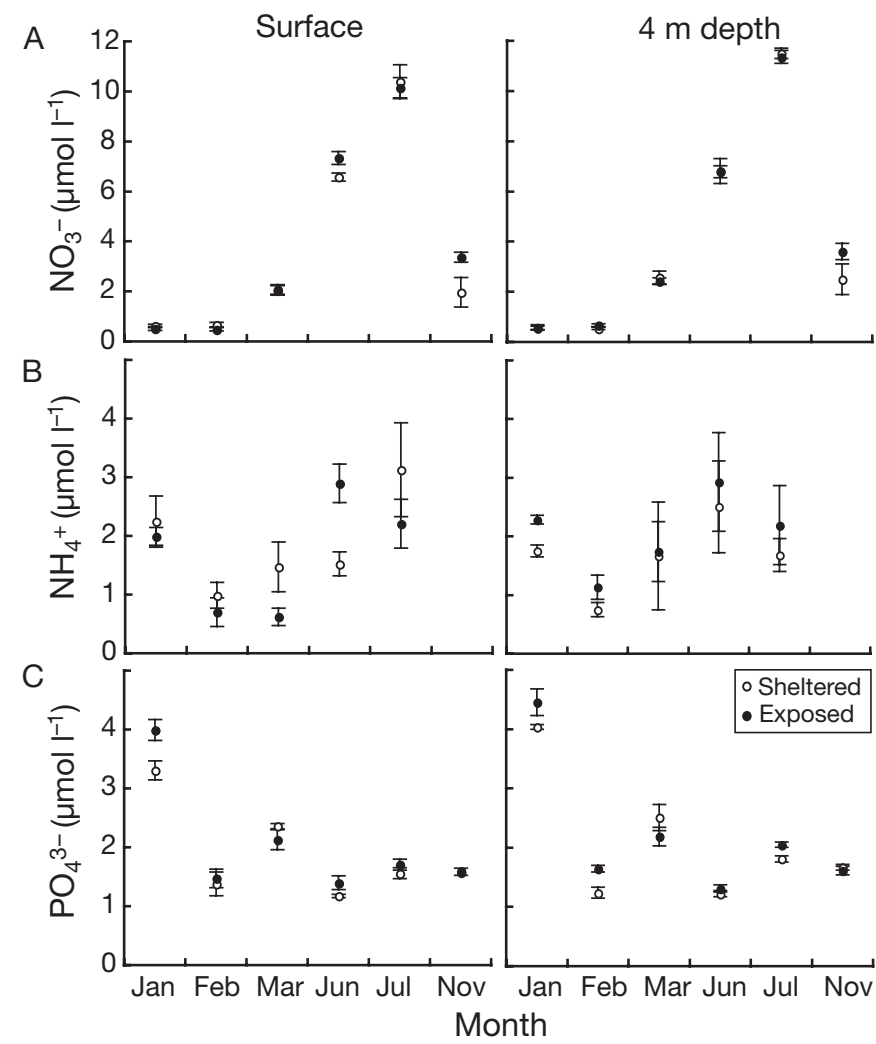

Fig. 3. (A) Nitrate, (B) ammonium, and (C) phosphate concentrations of seawater taken at surface and at $4 \mathrm{~m}$ depth from 8 sites within and near the entrance of Paterson Inlet, Stewart Island. Values represent means $\pm 1 \mathrm{SE}$ for $\mathrm{n}=4$. Ammonium concentrations from November are not included due to contamination

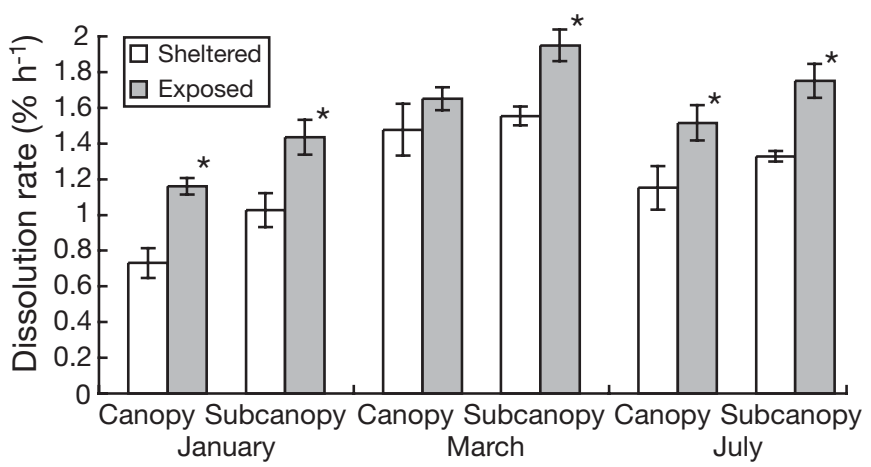

Fig. 4. Dissolution rates of gypsum blocks, as an indicator of mass-transfer rates at the blade surfaces of Macrocystis pyrifera, at wave-sheltered and wave-exposed sites in Paterson Inlet, Stewart Island at $1 \mathrm{~m}$ depth in the surface canopy and approximately $1 \mathrm{~m}$ above the benthos. Dissolution was determined over 3 separate 24 h periods: January (summer), March (autumn), July (winter) 2002. Values represent means $\pm 1 \mathrm{SE}(\mathrm{n}=4) .{ }^{*}$ Significant differences between wave-exposed and wave-sheltered sites within canopy groups (Tukey's test $\mathrm{p}=0.05)$

(Fig. 5, Table 2). During autumn, blade growth reached levels 4.3 times higher at wave-exposed sites than at wave-sheltered sites; stipe growth was 1.6 times higher. Significantly higher stipe growth rates were also observed during the summer. During the winter and spring tagging period blade and stipe growth was similar at wave-sheltered sites and waveexposed sites. New blade production rates did not follow a consistent pattern between wave-exposed and wave-sheltered sites over the study period (Fig. 5C, Table 2). New blade production rates were similar between wave-exposed and wave-sheltered sites during summer and spring. During autumn significantly

Table 1. Two-way ANOVA for dissolution rates of gypsum blocks attached to the surface of Macrocystis pyrifera blades at wave-exposed and wave-sheltered sites at 2 depths (canopy, subcanopy) over $24 \mathrm{~h}$ during January (summer), March (autumn), and July (winter) 2002

\begin{tabular}{|lrcc|}
\hline Factor & \multicolumn{1}{c}{$F$} & $\mathrm{df}$ & $\mathrm{p}$ \\
\hline January & & & \\
Regime & 25.76 & 1,12 & $<0.001$ \\
Depth & 11.93 & 1,12 & 0.005 \\
Regime $\times$ Depth & 0.02 & 1,15 & 0.90 \\
March & & & \\
Regime & 9.06 & 1,12 & 0.011 \\
Depth & 3.97 & 1,12 & 0.070 \\
Regime $\times$ Depth & 1.38 & 1,15 & 0.26 \\
July & & & \\
Regime & 17.88 & 1,12 & $<0.001$ \\
Depth & 4.89 & 1,12 & 0.047 \\
Regime $\times$ Depth & 0.98 & 1,15 & 0.760 \\
\hline
\end{tabular}


higher new blade production rates were observed at wave-exposed sites, however, this trend was reversed during winter. There was a significant interaction between season and water motion regime for all
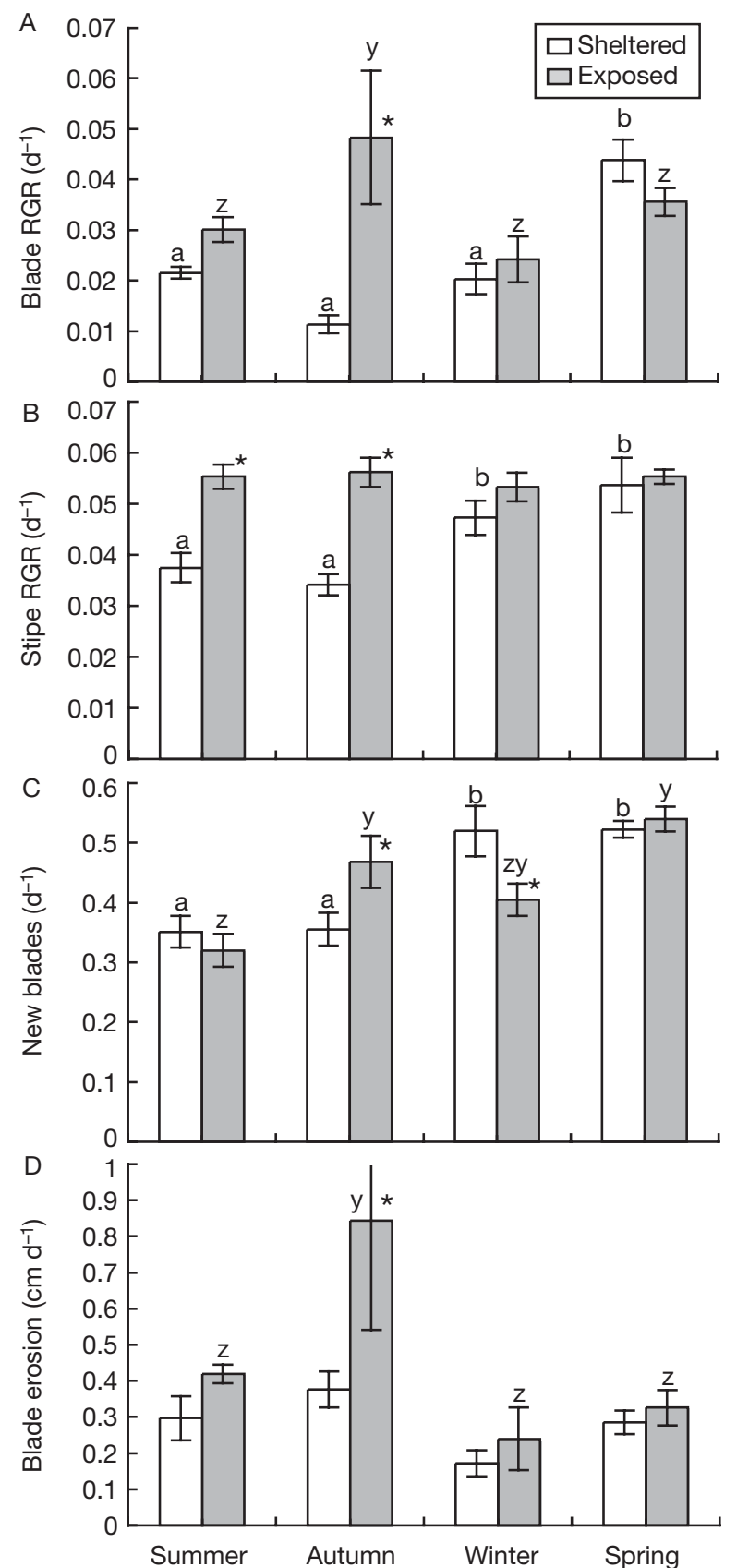

Fig. 5. Macrocystis pyrifera. Growth and erosion rates of fronds from wave-exposed and wave-sheltered sites at Paterson Inlet, Stewart Island, during summer, autumn, winter, and spring 2002. (A) Blade and (B) stipe relative growth rates (TGR). (C) Rate of production of new blades by the apical meristem. (D) Blade erosion rates. Bars represent means $\pm 1 \mathrm{SE}(\mathrm{n}=4)$. ${ }^{*}$ Significant differences between the growth/erosion rates of sites within sampling dates (post hoc Tukey's tests $p=0.05)$. $(a$, $b, y, z)$ Significant differences within sites among sampling dates growth parameters measured (Table 2). Only during autumn was a significant difference observed within a particular tagging period for blade erosion between wave-exposed and sheltered sites (Fig. 5D, Table 2). Blade erosion was over 2 times higher at waveexposed sites during this time, coinciding with a period of maximum blade growth.

Seasonal patterns of Macrocystis pyrifera blade and stipe growth strongly differed between wave-exposed and wave-sheltered sites (Fig. 5A,B). Wave-sheltered sites exhibited low blade and stipe growth during the summer and autumn that increased through winter to maxima during spring. In contrast, the summer and autumn depression in blade and stipe growth was not observed for wave-exposed sites and growth over different seasons was more consistent. In fact, maximal blade and stipe growth was observed in autumn for wave-exposed sites, a time when blade and stipe growth was at its lowest point for the year at wavesheltered sites. Seasonal patterns of blade erosion and new blade production were similar between wavesheltered and exposed sites (Fig. 5C,D).

\section{Macrocystis nitrogen and carbon status and isotopic composition}

A pattern of higher blade nitrogen status indicated by higher percentage nitrogen and low $\mathrm{C}: \mathrm{N}$ ratio was observed for canopy blades at wave-exposed sites compared to canopy blades at wave-sheltered sites (Fig. 6A,B, Table 3). Canopy blades had significantly higher nitrogen levels than subcanopy blades within

Table 2. Two-way ANOVA for growth and erosion parameters of Macrocystis pyrifera at wave-exposed and wave-sheltered sites at Paterson Inlet during the 4 seasons of 2002

\begin{tabular}{|lrrr|}
\hline Factor & \multicolumn{1}{c}{$F$} & $\mathrm{df}$ & \multicolumn{1}{c|}{$\mathrm{p}$} \\
\hline Blade growth & & & \\
Regime & 10.25 & 1,23 & 0.004 \\
Season & 5.69 & 3,23 & 0.005 \\
Season $\times$ Regime & 8.34 & 3,30 & $<0.001$ \\
Stipe growth & & & \\
Regime & 28.81 & 1,23 & $<0.001$ \\
Season & 3.61 & 3,23 & 0.029 \\
Season $\times$ Regime & 4.36 & 3,30 & 0.011 \\
New blades $\mathbf{d d}^{-\mathbf{1}}$ ) & & & \\
Regime & 0.82 & 1,23 & 0.366 \\
Season & 24.08 & 3,23 & $<0.001$ \\
Season $\times$ Regime & 5.81 & 3,30 & $<0.001$ \\
Erosion $\left(\mathbf{c m ~ d}^{-\mathbf{1}}\right.$ ) & & & \\
Regime & 6.90 & 1,23 & 0.015 \\
Season & 6.26 & 3,23 & 0.003 \\
Season $\times$ Regime & 2.06 & 3,30 & 0.133 \\
\hline
\end{tabular}



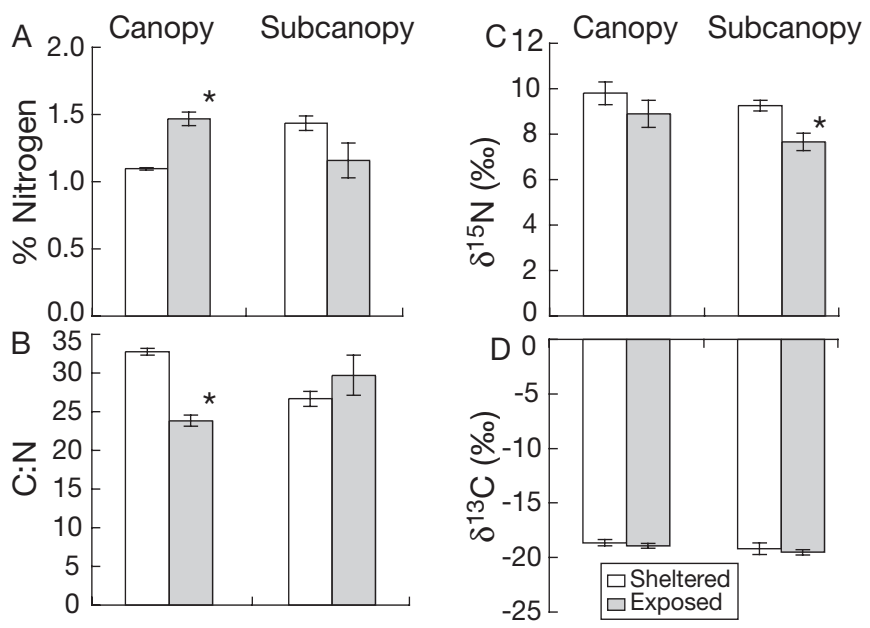

Fig. 6. Macrocystis pyrifera. Nitrogen status and nitrogen and carbon stable isotope signatures of blades collected from the surface canopy and from mature blades approximately $1 \mathrm{~m}$ above the benthos during January 2002. Values represent means \pm 1 SE $(n=4) .{ }^{*}$ Significant differences between sites within canopy and subcanopy groups (Tukey's test $\mathrm{p}=0.05$ )

Table 3. Macrocystis pyrifera. Two-way ANOVA for nitrogen and carbon status and composition of canopy and subcanopy blades at wave-exposed and wave-sheltered sites at Paterson Inlet during January 2002

\begin{tabular}{|lrcc|}
\hline Factor & \multicolumn{1}{c}{$F$} & $\mathrm{df}$ & $\mathrm{p}$ \\
\hline \% N & & & \\
Regime & 2.32 & 1,12 & 0.153 \\
Blade position (Depth) & 0.48 & 1,12 & 0.50 \\
Regime $\times$ Blade position & 11.67 & 1,15 & 0.005 \\
$\mathbf{C : N}$ & & & \\
Regime & 4.13 & 1,12 & 0.065 \\
Blade position (Depth) & 0.00 & 1,12 & 0.952 \\
Regime $\times$ Blade position & 17.26 & 1,15 & 0.001 \\
$\boldsymbol{\delta}^{13} \mathbf{C}$ & & & \\
Regime & 7.74 & 1,12 & 0.017 \\
Blade position (Depth) & 3.98 & 1,12 & 0.069 \\
Regime $\times$ Blade position & 0.57 & 1,15 & 0.463 \\
$\boldsymbol{\delta}^{15} \mathbf{N}$ & & & \\
Regime & 0.84 & 1,12 & 0.376 \\
Blade position (Depth) & 2.65 & 1,12 & 0.130 \\
Regime $\times$ Blade position & 0.01 & 1,15 & 0.939 \\
\hline
\end{tabular}

wave-exposed sites. At wave-sheltered sites this trend was reversed and higher nitrogen concentrations were observed in subcanopy blades, however these differences were only significant for $\mathrm{C}: \mathrm{N}$ ratios.

$\delta^{15} \mathrm{~N}$ of Macrocystis pyrifera blade tissue was lower at wave-exposed compared to wave-sheltered sites (Fig. 6C) but no difference was observed between hydrodynamic regimes within canopy blades. $\delta^{13} \mathrm{C}$ did not differ between wave-exposed and wave-sheltered sites or between canopy and subcanopy blades (Fig. 6D, Table 3).

\section{DISCUSSION}

Clear evidence of enhanced Macrocystis pyrifera growth was observed at wave-exposed sites for all growth parameters measured during the autumn. Oscillatory flow resulting from wave action enhanced nitrogen status and growth of $M$. pyrifera by reducing the thickness of diffusion boundary layers surrounding kelp thalli and by increasing the flux of nitrogen into dense surface kelp canopies. After a period of very low seawater nitrogen concentration and reduced frond growth during the summer, seawater nitrogen concentrations began to rise. Low tissue nitrogen concentrations at this time would have resulted in heightened nitrogen uptake affinities and metabolic demand for M. pyrifera during autumn (Hepburn et al. 2006). Increased flux of nitrogen to blade surfaces due to oscillatory flow most likely resulted in increased frond growth and nitrogen status at wave-exposed sites at a lower threshold of seawater nitrogen concentration than occurred in wave-sheltered sites as seawater nitrogen increased.

Evidence shows that Macrocystis pyrifera was nitrogen limited at the beginning of autumn as indicated by low growth rates and the $\mathrm{C}: \mathrm{N}$ ratios of blade tissue being well above the threshold ratio of 15 thought to indicate nitrogen limitation in macroalgae (Hanisak 1983). Nitrogen limitation was, however, less severe at wave-exposed sites. The average C:N ratios of canopy blade tissue, where the majority of growth occurs (Kain 1982) was lower at these sites $(\mathrm{C}: \mathrm{N}=24)$, indicating less severe nitrogen limitation, than at wave-sheltered sites $(\mathrm{C}: \mathrm{N}=33)$. The nitrogen concentration of canopy blade tissue from wave-sheltered sites $(1.1 \%)$ was at the critical value representing nitrogen exhaustion in M. pyrifera (Gerard 1982b), while nitrogen levels at wave-exposed sites (1.5\%) were well above this level.

Dissolution rates of gypsum blocks, an accurate estimate of diffusion boundary layer thickness and mass transfer rates in a range of hydrodynamic regimes (Porter 2000), were higher at the surfaces of Macrocystis pyrifera blades at wave-exposed sites. This supports the conclusion that diffusion boundary layers were significantly thinner, and as a result mass-transfer rates were greater, at wave-exposed compared to wavesheltered sites. Blades at wave-exposed sites exhibited greater blade base angles (i.e. a more 'streamlined' shape) than at wave-sheltered sites: an indication of long term (weeks to months) differences in hydrodynamic environment, and most likely a greater exposure to oscillatory flow (Hurd et al. 1996, Stevens et al. 2003).

Macrocystis pyrifera growth was most strongly affected by hydrodynamic regime during the autumn when blade tissue nitrogen was exhausted and sea- 
water nitrogen concentrations were at moderate levels. Some enhanced growth was observed during the summer when nitrogen concentrations were very low but these differences were only significant for the stipe. This could be a result of the very low seawater nitrogen concentrations observed at this time being unable to support high levels of growth, thus making rates of nutrient transport to the blade surface less important. Growth was similar in wave-exposed and wavesheltered sites during winter, a predictable result, as during this time high seawater nitrate concentrations probably saturated $M$. pyrifera nitrogen pools and growth was likely limited by light (Hepburn \& Hurd 2005). There was no evidence of increased light transmission through dense $M$. pyrifera canopies as a result of waves (Wing et al. 1993) enhancing growth during the winter. This could be a due to the lack of strong light limitation (growth remained relatively high during winter), as a result of the consistent high level of water clarity observed in Paterson Inlet during this study (C. D. Hepburn \& J. D. Holborow pers. obs.). The lack of enhanced growth at wave-exposed sites during spring is also understandable as growth at this time is strongly correlated with increasing light and growth is likely to be supported by tissue nitrogen pools accumulated during winter (Hepburn \& Hurd 2005).

Increased flux of nitrogen to Macrocystis pyrifera at wave-exposed sites could occur at the scale of the blade, frond, individual, canopy, or stand. At waveexposed sites rapid changes of flow direction cause flapping and reorientation of the blades, and provides turbulence at the macroalgal surface that can efficiently replenish nutrient depleted boundary layers at blade surfaces (Stevens \& Hurd 1997). Some wavesheltered sites in Paterson Inlet were subject to strong tidal flow without significant enhancement of growth compared to low flow and wave-exposed sites. Recent research using artificial canopies shows that velocities and mass-transfer rates are higher as a result of oscillatory flow compared to unidirectional flow (similar to that provided by tidal flow) of a similar magnitude without considering canopy movement (Lowe et al. 2005). M. pyrifera fronds are more static in unidirectional flows than in oscillatory flows, and blades, the major site for nutrient uptake (Gerard 1982c), are often streamlined behind the stipe and gas-filled bladders (C. D. Hepburn pers. obs.). Although flapping of seaweeds has been shown to occur in laminar flow rates as low as $6 \mathrm{~cm} \mathrm{~s}^{-1}$ (Koehl \& Alberte 1988, Hurd \& Stevens 1997) the amplitude of flapping is likely to be much lower than that observed for oscillatory flow. Clumping of fronds and reduced flow within closely packed frond bundles is also more likely to occur in relatively static M. pyrifera stands at wave-sheltered sites. For example, in low-flow environments, canopy compression at low tide may reduce nutrient uptake in Macrocystis spp. stands by as much as $50 \%$ (Stevens et al. 2003). Reduction in mass-transfer rates due to thallus compression as a result of high seawater velocities has been proposed to explain reduced carbon uptake and photosynthesis for bladed macroalgae in a strong unidirectional flow (Koehl \& Alberte 1988, Stewart \& Carpenter 2003). At the canopy or stand scale, wave action results in a dynamic stand structure with movement of M. pyrifera fronds on and off the seabed that may allow greater mixing between water within and outside the kelp canopy, and a greater flux of nutrients to M. pyrifera blade surfaces than in more static wavesheltered stands. Compression of the $M$. pyrifera stand as a whole can also occur in very strong currents when drag overcomes the buoyancy of fronds (Kain 1982, Gaylord et al. 2004), a process that was observed at some sites during the current study. As a result, skimming flows can develop above the canopy reducing mixing between water within the canopy and the rest of the water column (Koch \& Gust 1999, Gaylord et al. 2004). With reduced mixing, seawater within the canopy could be quickly stripped of nutrients due to the compression of a large amount of kelp tissue with high nutrient uptake capabilities into a small volume.

There was no evidence to suggest that the higher growth and nitrogen status of Macrocystis pyrifera during the summer and autumn were due to higher seawater nitrogen concentrations specific to waveexposed sites. Water samples were, however, taken only once or twice during a tagging period and short term pulses of high nitrate and ammonium, that are common in near shore environments (Zimmerman \& Kremer 1984), may not have been detected. $\delta^{15} \mathrm{~N}$ of $M$. pyrifera apical blade tissue was similar between waveexposed and wave-sheltered sites ( $<1 \%$ difference) during the period of low seawater nitrogen, suggesting that $M$. pyrifera at wave-exposed sites did not have access to exclusive nitrogen sources with distinct $\delta^{15} \mathrm{~N}$ values. These results suggest that localized nitrogensources were unlikely to have caused the enhanced growth observed during the summer and autumn and that increased nitrogen flux at the blade surface and into the canopy at wave-exposed sites is the most plausible explanation.

In contrast to canopy blades, nitrogen contents of subcanopy blades were lower at wave-exposed sites than those observed at wave-sheltered sites. Masstransfer rates were significantly higher at the base of fronds, probably a result of the lower density of kelp tissue below the surface canopy (Nyman et al. 1993) allowing increased flow rates. This may have allowed nitrogen flux to subcanopy blades to reach a critical level at wave-sheltered habitats resulting in increased blade nitrogen uptake and status at these sites. 
Exposure to waves also had a strong impact on the seasonal patterns of Macrocystis pyrifera growth. Low growth rates typical of $M$. pyrifera and other macroalgae during the summer low nitrogen period were not observed in areas exposed to wave action. M. pyrifera is known as a seasonal responder (Kain 1989) and its growth is often closely correlated to light and seawater nitrogen concentrations, particularly at higher latitudes (van Tussenbroek 1989, Hepburn \& Hurd 2005). This study provides evidence that wave action can modify this relationship primarily by ameliorating the effects of nitrogen limitation. The more consistent growth of $M$. pyrifera in wave-exposed sites could have important implications for secondary consumers reliant on kelp production. These results further emphasize the highly plastic nature of the seasonal growth patterns of $M$. pyrifera. Localized environmental factors such as light due to aspect, turbidity or weather patterns, or, as proposed by this study, nitrogen flux as a result of differences in the characteristics of water motion, can strongly modify seasonal growth patterns of $M$. pyrifera.

More research is warranted to determine if a consistent pattern of enhanced growth and/or production occurs in temperate macroalgal-based communities in response to exposure to waves during or following nitrogen limitation. Information is also required on the relative importance of different scales of water motion and macroalgal movement on the transmission of nutrients to macroalgal surfaces in different flow environments and nutrient concentrations.

Acknowledgements. The authors thank S. Bell, H. Kettles, A. Holborow, V. Sanchez, C. Garcia, D. Clement, S. Rutger, A. Hepburn, and C. Ireland for help with fieldwork. Thanks also goes to the Stewart Island Department of Conservation and their staff for logistical support, in particular A. Grey and P. Dobbins, and to A. Loughnan and L. Kregting for comments that help improve this paper. We appreciate the constructive recommendations of $\mathrm{M}$. Pederson and an anonymous referee during the review process. This work was funded by a University of Otago Research Grant to C.L.H, S.R.W., and R.D.F.

\section{LITERATURE CITED}

Brown MT, Nyman MA, Keogh JA, Chin NKM (1997) Seasonal growth of the giant kelp Macrocystis pyrifera in New Zealand. Mar Biol 129:417-424

Carpenter RC, Hackney JM, Adey WH (1991) Measurement of primary productivity and nitrogenase activity of coral reef algae in a chamber incorporating oscillatory flow. Limnol Oceanogr 36:40-49

Davison IR (1991) Environmental effects on algal photosynthesis: temperature. J Phycol 27:2-8

Dayton PK (1985) Ecology of kelp communities. Ann Rev Ecol Syst 16:215-245

Falter JL, Atkinson MJ, Merrifield MA (2004) Mass-transfer limitation of nutrient uptake by a wave-dominated reef flat community. Limnol Oceanogr 49:1820-1831

Foster MS, Schiel DR (1985) The ecology of giant kelp forests in California: a community profile. Biological report 85 (7.2), US Fish \& Wildlife Service, Washington, DC

France RL, Holmquist JG (1997) $\delta^{13} \mathrm{C}$ variability of macroalgae: effects of water motion via baffling by seagrasses and mangroves. Mar Ecol Prog Ser 149:305-308

Franklin LA, Forster RM (1997) The changing irradiance environment: consequences for marine macroalgal physiology, production and ecology. J Phycol 32:207-232

Fujita RM, Goldman JC (1985) Nutrient flux and growth of the red alga Gracilaria tikvahiae McLachlan (Rhodophyta). Bot Mar 28:265-268

Gaylord B, Reed DC, Washburn L, Raimondi PT (2004) Physical-biological coupling in spore dispersal of kelp forest macroalgae. J Mar Syst 49:19-39

Gerard VA (1982a) In situ water motion and nutrient uptake by the giant kelp Macrocystis pyrifera. Mar Biol 69:51-54

Gerard VA (1982b) Growth and utilization of internal nitrogen reserves by the giant kelp Macrocytis pyrifera in a low-nitrogen environment. Mar Biol 66:27-35

Gerard VA (1982c) In situ rates of nitrate uptake by giant kelp Macrocystis pyrifera: tissue differences, environmental effects, and predictions of nitrogen limited growth. J Exp Mar Biol Ecol 62:211-224

Gerard VA, Mann KH (1979) Growth and production of Laminaria longicruris (Phaeophyta) populations exposed to different intensities of water movement. J Phycol 15:33-41

Handley LL, Raven JA (1992) The use of natural abundance of nitrogen isotopes in plant physiology and ecology. Plant Cell Environ 15:965-985

Hanisak MD (1983) The nitrogen relationships of marine macroalgae. In: Carpenter EJ, Capone DG (eds) Nitrogen in the marine environment. Academic Press, New York, p 699-730

Hepburn CD, Hurd CL (2005) Conditional mutualism between the giant kelp Macrocystis pyrifera and colonial epifauna. Mar Ecol Prog Ser 302:37-48

Hepburn CD, Hurd CL, Frew RD (2006) Colony structure and seasonal differences in light and nitrogen modify the impact of sessile epifauna on the giant kelp Macrocystis pyrifera (L.) C Agardh. Hydrobiologia 560:373-383

Hurd CL (2000) Water motion, marine macroalgal physiology, and production. J Phycol 36:453-472

Hurd CL, Stevens CL (1997) Flow visualization around singleand multiple-bladed seaweeds with various morphologies. J Phycol 33:360-367

Hurd CL, Harrison PJ, Druehl LD (1996) Effect of seawater velocity on inorganic nitrogen uptake by morphologically distinct forms of Macrocystis integrifolia from wavesheltered and exposed sites. Mar Biol 126:205-214

Kain JM (1982) Morphology and growth of Macrocystis pyrifera in New Zealand and California. Mar Biol 67: $143-157$

Kain JM (1989) The seasons in the subtidal. Br Phycol J 24: 203-215

Koch EW (1993) The effect of water flow on photosynthetic processes of the alga Ulva lactuca L. Hydrobiologia 260/261:457-462

Koch EW, Gust G (1999) Water flow in tide- and wavedominated beds of the seagrass Thalassia testudinum. Mar Ecol Prog Ser 184:63-72

Koehl MAR, Alberte RS (1988) Flow, flapping, and photosynthesis of Nereocystis leutkeana: a functional comparison of undulate and flat blade morphologies. Mar Biol 99: 435-444 
Lowe RJ, Koseff JR, Monismith SG, Falter JL (2005) Oscillatory flow through submerged canopies. 2. Canopy mass transfer. J Geophys Res 110:C10017, doi:10.1029/2004 JC002789

Nyman MA, Brown MT, Neushul M, Harger BWW, Keogh JA (1993) Mass distribution in the fronds of Macrocystis pyrifera from New Zealand and California. Hydrobiologia 260-261:57-65

Parker HS (1982) Effects of simulated current on the growth rate and nitrogen metabolism of Gracilaria tikvahiae (Rhodophyta). Mar Biol 69:137-145

Porter ET, Lawrence PS, Suttles SE (2000) Gypsum dissolution is not a universal integrator of 'water motion'. Limnol Oceanogr 45:145-158

Raven JA, Walker DI, Johnston AM, Handley LL, Kübler JE (1995) Implications of the ${ }^{13} \mathrm{C}$ natural abundance measurements for photosynthetic performance by marine macrophytes in their natural environment. Mar Ecol Prog Ser 123:193-205

Sanford LP, Crawford SM (2000) Mass transfer versus kinetic control across solid-water boundaries. Limnol Oceanogr 45:1180-1186

Sjøtun K, Fredriksen S, Rueness J (1998) Effect of canopy biomass and wave exposure on growth in Laminaria hyperborea (Laminariaceae, Phaeophyta). Eur J Phycol 33: 337-343

Steneck RS, Graham MH, Bourque BJ, Corbett D, Erlandson JM, Estes JA, Tegner MA (2002) Kelp forest ecosystems:

Editorial responsibility: Howard Browman (Associate Editorin-Chief), Storebø, Norway biodiversity, stability, resilience, and future. Environ Conserv 29:436-459

Stevens CL, Hurd CL (1997) Boundary-layers around bladed aquatic macrophytes. Hydrobiologia 346:119-128

Stevens CL, Hurd CL, Isachsen PE (2003) Modelling of diffusion boundary-layers in subtidal macroalgal canopies: the response to waves and currents. Aquat Sci 65:81-91

Stewart HL, Carpenter RC (2003) The effects of morphology and water flow on photosynthesis of marine macroalgae. Ecology 84:2999-3012

Taylor RB, Rees TAV (1998) Excretory products of mobile epifauna as a nitrogen source for seaweeds. Limnol Oceanogr 43:600-606

Thomas FIM, Cornelison CD, Zande JM (2000) Effects of water velocity and canopy morphology on ammonium uptake by seagrass communities. Ecology 81:2704-2713

van Tussenbroek BI (1989) Seasonal growth and composition of fronds of Macrocystis pyrifera in the Falkland Islands. Mar Biol 100:419-430

Wheeler WN (1980) Effect of boundary layer transport on the fixation of carbon by the giant kelp Macrocystis pyrifera. Mar Biol 56:103-110

Wing SR, Leichter JJ, Denny MW (1993) A dynamic model for wave induced fluctuations in a kelp forest. Limnol Oceanogr 38:396-407

Zimmerman RC, Kremer JN (1984) Episodic nutrient supply to a kelp forest ecosystem in Southern California. J Mar Res 42:591-604

Submitted: January 13, 2006; Accepted: September 28, 2006 Proofs received from author(s): May 1, 2007 